\title{
Nurses and physicians point of view regarding causes of conflict between them and resolution strategies used
}

\author{
Dalal T. Akel ${ }^{*}$ Hemat Abd Elazeem \\ Nursing Administration Department, Faculty of Nursing, Ain Shams University, Egypt
}

Received: August 26, 2015

Accepted: October 11, $2015 \quad$ Online Published: October 22, 2015

DOI: $10.5430 / \mathrm{cns} . v 3 \mathrm{n} 4 \mathrm{p} 112$

URL: http://dx.doi.org/10.5430/cns.v3n4p112

\begin{abstract}
Nursing is profession based on collaborative relationships with clients or patients and colleagues. Nurses who effectively deal with conflict demonstrating respect for their clients, their colleagues and the profession. This study was aimed at comparing between nurses and physicians point of view regarding causes of conflict between the first party and resolution strategies used. An analytic cross-sectional design was used in this study which was carried out in various medical departments and intensive care units at Ain Shams University Medical Hospital. A convenient sampling method was used to include 132 nurses and 139 physicians in this study. The researcher used two self-administrative questionnaires namely the conflict causes questionnaire and Thomas-Kilmann conflict mode instrument (TKI). Results demonstrates statistically significant differences between nurses and physicians in five out of the seven categories of factors that may cause conflict between them. The accommodative strategy was the most used by both nurses and physicians. The study concluded that the conflict resolution strategy most commonly used by both categories is the "accommodating strategy". The study recommends that health professionals must develop communication and interpersonal skills and understanding of causes, approaches and strategies of conflict management.
\end{abstract}

Key Words: Conflict causes, Resolution strategies, Nurses, Physicians

\section{INTRODUCTION}

Health care teams consist of members from different professions and disciplines, the two most important are nursing and medical ones. Although they may have different backgrounds they must work together in harmony to provide quality care for their patients. Nonetheless, such differences may be the sources of conflicts defined as a power struggle in which a person intends to harass, neutralize, injure or eliminate a rival. ${ }^{[1]}$ If excessive, conflicts may jeopardize the care provided to patients. ${ }^{[2]}$ In addition, conflict among colleagues can lead to antagonistic and passive-aggressive behaviors that compromise the therapeutic nurse-client relationship. ${ }^{[3]}$

Nurse/Physician conflict is a type of group conflict. It may arise from difference in perception that may be caused due to the different sources of information, different techniques adopted for processing the information, and different goals. ${ }^{[4]}$ They can also be attributed to personal differences such as gender, educational gap and socio-economic state, misunderstanding and incompatibility, and the recent decision of nurses to undertake greater responsibilities. ${ }^{[5]}$ Meanwhile, evidence shows that successful nurse-physician relationship is associated with positive attitudes of nurses and physicians towards patients, and consequently higher quality of health care. ${ }^{[6]}$ A study in Egypt revealed that physicians were more satisfied than nurses with their relationships, but they perceive their relationships with nurses as superior and subordinate. ${ }^{[7]}$

\footnotetext{
*Correspondence: Dalal T. Akel; Email: dalalakel@ hotmail.com; Address: Nursing Administration Department, Faculty of Nursing, Ain Shams University, Cairo, Egypt.
} 
Managing conflict towards constructive action is the best approach in resolving conflict in organization. ${ }^{[8]}$ Conflict resolution strategies are essential to effectively deal with conflict. The conflicting parties may sit together and discuss their own needs in the overall organizational perspective. ${ }^{[4]}$ Hence, nurse managers should establish systems that facilitate the development of conflict-resolution skills for all members of the health care team. ${ }^{[9]}$ Moreover, many nursing associations and colleges are committed to helping nurses recognize and manage conflict in the practice setting. ${ }^{[10]}$

Therefore, it is important for nurse managers to understand the types of conflict and their sources so that they can find the appropriate techniques to deal with them. They must be aware of the ways in which conflict can escalate and be prepared to prevent or manage it in the workplace. Accordingly, our aim is to compare between nurses and physicians point of view regarding causes of conflict between them and resolution strategies used.

\section{Research questions}

(1) What are the differences in causes of conflicts between nurses and physicians?

(2) What are the differences of strategic resolution used between nurses and physicians?

\section{MeThODS}

\subsection{Study design}

An analytic cross-sectional design was used in this study.

\subsection{Sample and setting}

The study was carried out in various medical departments and intensive care units at Ain Shams University Medical Hospital.

\subsubsection{Sample criteria}

Nurses and physicians in the study setting were eligible for the study with the inclusion criteria of being full time working and providing direct care activities for the patients at the time of data collection. Those on long leaves were excluded.

\subsubsection{Sample size}

The sample size was calculated to detect any difference between nurses and physicians' source of conflict with a prevalence $20 \%$ or higher $\left(p_{1}=20 \%\right)$ and an Odds Ratio 2.1 or higher $\left(p_{2}=35 \%\right)$ with a $95 \%$ level of confidence and a study power of $80 \%(\beta$ error $=20 \%)$. Using the equation for the difference between two proportions (EpiInfo 6.04), the estimated sample size is 132 nurses and 139 physicians after increasing the sample by about $10 \%$ to compensate for expected non-responses.

Published by Sciedu Press

\subsubsection{Sampling technique}

A convenient sampling method was used to recruit nurses and physicians according to the eligibility criteria set.

\subsection{Tools of data collection}

The researcher used a self-administrative questionnaire with a section for nurses and physicians' demographic characteristics and two scales, namely the conflict causes questionnaire and Thomas-Kilmann conflict mode instrument (TKI). The conflict causes scale was be developed by the researchers based on a review of pertinent literature. ${ }^{[11,12]}$ It includes 50 statements on a 5-point Likert scale ranging from "strongly agree" to "strongly disagree" covering seven categories: Personality differences (9 items), Failed communication (13 items), Differences in job status (12 items), Workload (4 items), Time pressure (3 items), Level of education (4 items) and Job authorities (5 items). The responses from "strongly agree" to "strongly disagree" were scored respectively from 5 to 1 . The scores of the statements of each category were summed-up, converted into percent score, and the total divided by the number of the items, and converted into a percent score. The nurse/physician was considered to have a high level of agreement upon the factors if the total score obtained was $60 \%$ or higher (corresponding to agree and strongly agree), and low if the total score was less than $60 \%$ (corresponding to the responses: uncertain, disagree, and strongly disagree). The tool was vigorously revised by juries for face and content validity.

The TKI was developed by Kilmanm and Thomas ${ }^{[13]}$ for measuring the five conflict management strategies which are: competing, collaborating, compromising, avoiding, and accommodating. It consists of 30 pairs of items (A and B) for a total of 60 items. Each 6 pairs (12 items) measure one strategy. The respondent has to select either A or B for each of the 30 pairs. The scoring was done according to the tool guidelines. ${ }^{[13]}$

The reliability of these two scales was done through assessing their internal consistency expressed as Cronbach alpha coefficients. The scales proved to have good reliability coefficients: 0.86 and 0.64 respectively.

\subsubsection{Pilot study}

A pilot study was held on about $10 \%$ of the number of nurses and physicians required for the study. The aim was to determine the applicability, clarity, and feasibility of the tool, and the time needed for filling the forms. Few modifications were done based on the results of the pilot, in the form of re-phrasing or re-wording of some statements. The tool was then put in its finalized form. 


\subsubsection{Fieldwork}

Upon official approval guaranteed, the researcher met with the nurses and physicians and invited them to participate af ter explaining the study purpose and procedures. Those who gave their consent were handed the data collection tool and instructed on how to fill them. The researcher was present all the time for any clarifications required. The time consumed for filling the form was approximately 30-40 minutes. It took 60 minutes in some cases due to external interruptions. The total time of data collection was 12 months.

\subsubsection{Limitations of the study}

Ten participant nurses did not complete the forms and were excluded from analysis; however this was within the expected percentage of dropout. Also, it was difficult to for some participants to fill-out the questionnaire in one setting especially in busy departments as intensive care units. This led to longer time consumed in the data collection process.

\subsection{Data analysis}

Data entry and statistical analysis were progressed using SPSS 16.0 statistical software package. Data were presented using descriptive statistics in the form of frequencies and percentages for qualitative variables, and means and standard deviations and medians for quantitative variables. Cronbach alpha coefficient was calculated to assess the reliability of the developed tools through their internal consistency. Qualitative categorical variables were compared using chi-square test. Spearman rank correlation was used for assessment of the inter-relationships among quantitative variables and ranked ones. In order to identify the independent predictors of the conflict causes score multiple linear regression analysis was used after testing for normality, and homoscedasticity, and analysis of variance for the full regression models were done. Statistical significance was considered at $p$-value $<$ .05 .

Table 1. Socio-demographic characteristics of nurses and physicians in the study sample

\begin{tabular}{|c|c|c|c|c|}
\hline & \multicolumn{2}{|c|}{ Nurses $(n=132)$} & \multicolumn{2}{|c|}{ Physicians ( $n=139)$} \\
\hline & No. & $\%$ & No. & $\%$ \\
\hline \multicolumn{5}{|l|}{ Age } \\
\hline$<30$ & 59 & 44.7 & 49 & 35.2 \\
\hline $30-40$ & 48 & 36.4 & 56 & 40.3 \\
\hline $40+$ & 25 & 18.9 & 34 & 24.5 \\
\hline Range & $22.0-55.0$ & & $25.0-58.0$ & \\
\hline Mean \pm SD & $32.3 \pm 8.6$ & & $32.3 \pm 8.6$ & \\
\hline Median & 30.00 & & 32.0 & \\
\hline \multicolumn{5}{|l|}{ Sex } \\
\hline Male & 33 & 25.0 & 78 & 56.1 \\
\hline Female & 99 & 75.0 & 61 & 43.9 \\
\hline \multicolumn{5}{|l|}{ Current marital status } \\
\hline Unmarried & 62 & 47.0 & 64 & 46.0 \\
\hline Married & 70 & 53.0 & 75 & 54.0 \\
\hline \multicolumn{5}{|l|}{ Qualification } \\
\hline Diploma & 67 & 50.8 & & \\
\hline Bachelor & 63 & 47.7 & 48 & 34.5 \\
\hline Postgraduate & 3 & 2.3 & 91 & 65.5 \\
\hline \multicolumn{5}{|l|}{ Experience years } \\
\hline$<5$ & 27 & 20.5 & 55 & 39.5 \\
\hline $5-10$ & 52 & 39.4 & 35 & 25.2 \\
\hline $10+$ & 53 & 40.1 & 49 & 35.3 \\
\hline Range & $1.0-35.0$ & & $1.0-34.0$ & \\
\hline Mean \pm SD & $10.8 \pm 8.0$ & & $9.3 \pm 8.2$ & \\
\hline Median & 8.0 & & 6.5 & \\
\hline \multicolumn{5}{|l|}{ Job position (nurses) } \\
\hline Head nurse & 75 & 56.8 & & \\
\hline Staff nurse & 57 & 43.2 & & \\
\hline \multicolumn{5}{|l|}{ Job position (physicians) } \\
\hline Resident & & & 36 & 26.0 \\
\hline Specialist & & & 48 & 34.5 \\
\hline Consultant & & & 55 & 39.5 \\
\hline Attended training in conflict & 12 & 6.8 & 1 & 0.5 \\
\hline
\end{tabular}


Table 1 shows that nurses' age ranged between 22 and 55 years, with a majority of females $(75 \%)$. Slightly less than half of them were unmarried (47.0\%) and were having a bachelor degree in nursing $(47.7 \%)$. Their experience years ranged between one and 35 years with a median of 8 years. Slightly more than two-fifth of the nurses had the position of staff nurse $(43.2 \%)$. Concerning physicians, their age ranged between 25 and 58 years, with a slightly higher percent- age of males (56.1\%). Slightly less than half of them were unmarried (46.0\%) and approximately two thirds were having a postgraduate degree (65.5\%). Their experience years ranged between one and 34 years with a median of 6.5 years. Slightly more than one third of them were specialists (34.5\%) or consultants (39.5\%). A lower percentage of physicians $(0.5 \%)$ than nurses $(6.8 \%)$ had attended training in conflict.

Table 2. Comparison of nurses and physicians' agreement upon the total causes of conflict

\begin{tabular}{|c|c|c|c|c|c|c|}
\hline & \multicolumn{4}{|c|}{ Group } & \multirow{3}{*}{$\chi^{2}$ test } & \multirow{3}{*}{$p$-value } \\
\hline & \multicolumn{2}{|c|}{ Nurses $(n=132)$} & \multicolumn{2}{|c|}{ Physicians $(n=139)$} & & \\
\hline & No. & $\%$ & No. & $\%$ & & \\
\hline \multicolumn{7}{|l|}{ High agreement upon } \\
\hline Personality differences & 116 & 87.9 & 115 & 82.7 & 2.6 & .05 \\
\hline Failed communication & 109 & 82.6 & 86 & 61.9 & 20.4 & $<.001^{*}$ \\
\hline Difference in job status & 118 & 89.4 & 63 & 48.5 & 77.6 & $<.001^{*}$ \\
\hline Workload & 108 & 81.8 & 132 & 95.0 & 13.8 & $<.001^{*}$ \\
\hline Time pressure & 125 & 94.7 & 112 & 80.6 & 17.9 & $<.001^{*}$ \\
\hline Level of education & 127 & 96.2 & 126 & 90.6 & 2.4 & .12 \\
\hline Job authorities & 67 & 50.8 & 19 & 13.7 & 54.3 & $<.001^{*}$ \\
\hline \multicolumn{7}{|l|}{ Total } \\
\hline Agree $(70 \%+)$ & 121 & 91.7 & 100 & 71.9 & & \\
\hline Disagree (< 70\%) & 11 & 8.3 & 39 & 28.1 & 21.8 & $<.001^{*}$ \\
\hline
\end{tabular}

* Statistically significant at $p<.05$

Table 2 demonstrates statistically significant differences between nurses and physicians in five out of the seven categories of factors that may cause conflict between them. The agreement was higher among nurses in all categories except that of workload, which was higher among physicians (95\%) compared with nurses (81.8\%). Meanwhile, no differences of statistical significance were revealed in the categories of personality differences and level of education. A higher total agreement upon the factors that may cause conflict is revealed among nurses (91.7\%) compared with physicians $(71.9 \%), p<.001$.

When comparing the nurses and physicians' conflict resolution strategies (see Table 3), the only difference of statistical significance was in the compromising strategy $(p=.001)$. It is evident that this strategy was used more used by physicians $(23.7 \%)$ compared with nurses $(10.6 \%)$. The table also shows that the accommodating strategy was the most used by both nurses $(38.6 \%)$ and physicians $(28.1 \%)$.

Examining the correlations between nurses' agreement upon the causes of conflict and their used resolution strategies, Table 4 demonstrates weak statistically positive correlation between agreement and competing strategy, and negative correlation with collaborating strategy. The table also shows weak to moderate statistically negative correlations between competing strategy and all other strategies. It also shows weak statistically negative correlations between collaborating and compromising $(\mathrm{r}=-.223)$ and compromising and accommodating (- .352).

As for physicians, the table points to a weak statistically negative correlation between agreement and competing strategy, and positive correlations with collaborating, compromising, and avoiding strategies. The table also shows weak to moderate statistically negative correlations between competing strategy and all other strategies except the accommodating. It also shows weak statistically negative correlations between the accommodating strategy and the collaborating $(r=-.347)$, compromising $(\mathrm{r}=-.228)$ and avoiding $(-.154)$ strategies.

Table 5 demonstrates a weak statistically positive correlation between nurses' agreement upon conflict causes and their qualification, and a weak negative correlation with their use of collaborating strategy. Concerning physicians, a weak statistically negative correlation is revealed between their age and use of compromising strategy. Their qualification and experience had a positive correlation with their use of competing strategy, and negative correlations with their agreement upon causes, and the use of collaborating and compromising strategies. 
Table 3. Comparison of nurses and physicians' conflict resolution strategies

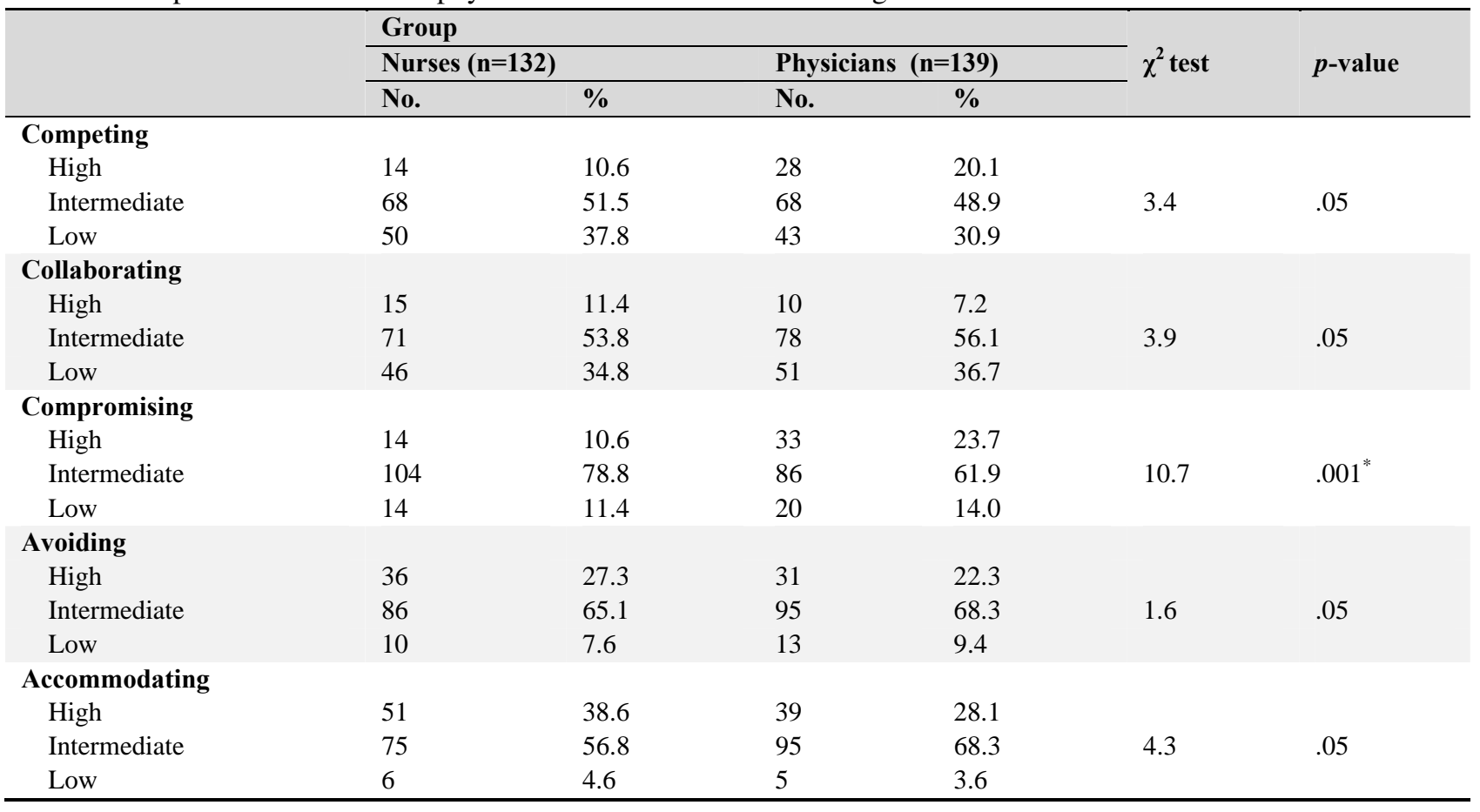

* Statistically significant at $p<.05$

In multivariate analysis (see Table 6), the best fitting regression model identified being a nurse, increasing age, female gender, and the more use of compromising strategy as the positive independent statistically significant predictors of a higher score of agreement upon conflict causes. On the other hand, the increasing experience years as negative predictors of the agreement score.

Table 4. Correlation between scores of conflict causes and resolution strategies a) Nurses

\begin{tabular}{|c|c|c|c|c|c|c|}
\hline \multirow{2}{*}{ Feelings } & \multicolumn{6}{|c|}{ Spearman's rank correlation coefficient } \\
\hline & Conflict causes & Competing & Collaborating & Compromising & Avoiding & Accommodating \\
\hline \multicolumn{7}{|l|}{ Conflict causes } \\
\hline \multicolumn{7}{|c|}{ Resolution strategies: } \\
\hline Competing & $.217^{* *}$ & & & & & \\
\hline Collaborating & $-.216^{* *}$ & $-.518^{* *}$ & & & & \\
\hline Compromising & 0.08 & $-.187^{*}$ & $-.224^{* *}$ & & & \\
\hline Avoiding & -0.09 & $-.420^{* *}$ & -0.09 & -0.08 & & \\
\hline Accommodating & -0.05 & $-.293^{* *}$ & -0.08 & $-.351^{* *}$ & -0.07 & \\
\hline
\end{tabular}

${ }^{*}$ Statistically significant at $p<.05 ;{ }^{* *}$ Statistically significant at $p<.01$

b) Physicians

\begin{tabular}{lllllll}
\hline \multirow{2}{*}{ Feelings } & \multicolumn{6}{l}{ Spearman's rank correlation coefficient } \\
\cline { 2 - 6 } & Conflict causes & Competing & Collaborating & Compromising & Avoiding & Accommodating \\
\hline Conflict causes & & & & & \\
Resolution strategies & & & & & \\
Competing & $-.394^{* *}$ & & & & \\
Collaborating & $.242^{* *}$ & $-.447^{* *}$ & & & \\
Compromising & $.192^{* *}$ & $-.620^{* *}$ & 0.11 & & \\
Avoiding & $.231^{* *}$ & $-.302^{* *}$ & -0.05 & -0.12 & \\
Accommodating & -0.04 & -0.13 & $-.345^{* *}$ & $-.226^{* *}$ & $-.153^{*}$ & \\
\hline
\end{tabular}

${ }^{*}$ Statistically significant at $p<.05 ;{ }^{* *}$ Statistically significant at $p<.01$ 


\section{DiscuSSION}

Although physicians and nurses play critical roles in providing team-based collaborative care, the literature on current relationships between physicians and nurses in typical health care settings reveals troublesome characteristics that affect the quality of the patient care that they provide. ${ }^{[14]}$ This study aimed to compare between nurses and physicians point of view regarding causes of conflict between them and resolution strategies used.

The findings indicate generally different agreement upon the causes of conflict between nurses and physicians, and also in the conflict management strategies pursued by them.

Table 5. Correlation between scores of conflict causes and resolution strategies and their socio-demographic characteristics

\begin{tabular}{|c|c|c|c|}
\hline & \multicolumn{3}{|c|}{ Spearman's rank correlation coefficient } \\
\hline & Age & Qualification & Experience \\
\hline \multicolumn{4}{|l|}{ Nurses } \\
\hline Conflict causes & 0.00 & $.278^{* *}$ & -0.13 \\
\hline \multicolumn{4}{|c|}{ Resolution strategies: } \\
\hline Competing & 0.04 & 0.13 & -0.05 \\
\hline Collaborating & -0.08 & $-.231^{* *}$ & 0.04 \\
\hline Compromising & 0.06 & -0.05 & 0.12 \\
\hline Avoiding & -0.06 & 0.03 & -0.07 \\
\hline Accommodating & 0.05 & 0.11 & -0.04 \\
\hline \multicolumn{4}{|l|}{ Physicians } \\
\hline Conflict causes & -0.14 & $-.231^{* *}$ & $-.199^{* *}$ \\
\hline \multicolumn{4}{|c|}{ Resolution strategies: } \\
\hline Competing & 0.14 & $.204^{* *}$ & $.215^{* *}$ \\
\hline Collaborating & -0.14 & $-.225^{* *}$ & $-.241^{* *}$ \\
\hline Compromising & $-.203^{* *}$ & $-.172^{*}$ & $-.216^{* *}$ \\
\hline Avoiding & 0.12 & 0.04 & 0.06 \\
\hline Accommodating & 0.07 & 0.07 & 0.09 \\
\hline
\end{tabular}

${ }^{*}$ Statistically significant at $p<.05 ;{ }^{* *}$ Statistically significant at $p<.01$

The present study revealed that the factors related to the level of education had the highest percentage of agreement among nurses, and the second highest among physicians as a potential cause of conflict between nurses and physicians. Also, the findings showed a high agreement in both groups upon the value of higher nurses' qualification since many problems may be solved through better nursing qualification. In agreement with this, McKie, et al. ${ }^{[15]}$ reported better communication skills with higher qualification level among nurses in the United Kingdom.

Table 6. Best fitting multiple linear regression model for the conflict causes score

\begin{tabular}{llllllll}
\hline & \multicolumn{2}{l}{ Unstandardized Coefficients } & Standardized & t-test & & \multicolumn{2}{c}{ 95\% Confidence Interval for B } \\
\cline { 2 - 3 } & B & Std. Error & Coefficients & & & Lower & Upper \\
\hline Constant & 71.3 & 2.23 & & 31.958 & $<.001$ & 66.9 & 75.63 \\
Group (reference: nurse) & -3.7 & 0.7 & -0.4 & -5.58 & $<.001$ & -5.0 & -2.38 \\
Age & 0.3 & 0.2 & 0.4 & 2.47 & .015 & 0.05 & 0.39 \\
Sex (reference: male) & 1.2 & 0.6 & 0.2 & 2.06 & .042 & 0.06 & 2.26 \\
Experience & -0.27 & 0.09 & -0.42 & -2.84 & .005 & -0.46 & -0.09 \\
Compromising & 0.29 & 0.16 & 0.13 & 1.95 & .054 & 0.00 & 0.56 \\
\hline
\end{tabular}

r-square $=0.12$; Model ANOVA: $\mathrm{F}=10.37, p<.001$; Variables entered and excluded: qualification, marital status, job, other conflict resolution scores

Regarding to the time pressure dimension as a cause of conflict between nurses and physicians came second highest in agreement ranking among nurses; this dimension includes factors such as the lack of adequate time schedule, lack of 
the work of the nurses, although both believe in the importance of constructing time schedule and adhering to it in order to mitigate conflicts. Consequently, when set rules may not be followed in times of work pressure, empathy is essential to overcome such difficult situations. In this regard, Svenaeus ${ }^{[16]}$ stressed that empathy is constantly asked for as a central skill and character trait of the good physician and nurse. It is a source of moral knowledge and is also a motivation for acting in a good way.

Furthermore, the dimension of failed communication as a cause of conflict between nurses and physicians showed significantly higher agreement among the nurses in the current study. This is expected due to differential look at the communication between both parties. In line with this, McLennon, et al. ${ }^{[17]}$ informed that nurses were better in facilitating communication strategies. Moreover, nurses viewed some lack of respect from the side of physicians towards them, which may be the source of conflicts. Lyndon, et al. ${ }^{[18]}$ found similar disrespect between physicians and nurses in the United States, and this contributed to decisions to resign or quit due to negative feelings of defeatism and low self-esteem.

The present study has also demonstrated a significantly higher agreement among nurses upon the "differences in job status" as causes of conflict, with an almost double percentage. The finding reflects nurses' feeling of prejudice of hospital administration against them whenever physicians are involved, and that they view themselves as the oppressed party. This sort of inferiority feeling would certainly be a major source of conflicts between physicians and nurses. In agreement with this, Cummings, et al. ${ }^{[19]}$ identified administration and supervisor support in resolving conflict as a major factor influencing job satisfaction among Canadian nurses.

Concerning the dimension of job authorities, it had the least agreement among nurses and physicians of the current study, although nurses' agreement was significantly higher. This might be due to the fact that more nurses viewed that there is a conflict between the professional authorities of both physicians and nurses, with conflicts concerning practicing and emphasizing their authorities. Regarding to the pervious, Muller-Juge, et al. ${ }^{[20]}$ in Switzerland stated that most resident-nurse pairs tended to interact in a traditional way, with residents taking the leadership and nurses executing medical prescriptions. Accordingly, McAndrew, et al. ${ }^{[21]}$ emphasized the importance of improving nurse's sense of control over practice, teamwork, communication, and autonomy.

Related to the present study results, the workload dimension as a possible cause of conflict was the only one that had a significantly higher agreement among physicians. This might be due to that more physicians may view that the nurse has to cope with their bad temper in extreme workloads, but less nurses see that physicians tolerate their low performance in these situations. In line with this finding, Di Giulio, et $a l .{ }^{[22]}$ identified workload as the most common problem threatening good communication and collaboration between physicians and nurses in Italy.

In total, the present study results showed that nurses and physicians have significantly different views of the various categories of factors that may cause conflict between them. So, more nurses agreed upon the factors related to failed communication, differences in job status, time pressure, and job authorities. On the other hand, more physicians agreed upon the factors related to workload. Meanwhile, no differences were revealed regarding personality differences and the level of education. Overall, the total agreement upon the factors that may cause conflict turned to be higher among nurses compared with physicians. The findings indicate that the nurses are more concerned about the factors related to communication and authorities than with workload.

Therefore, the conflict resolution strategies used by the nurses and physicians, the current study revealed that more physicians used the compromising strategy compared with nurses, and this was the only significant difference between them. This might be explained by the fact that this resolution strategy necessitates more ability of taking risk and making decision, which nurses may feel they are not capable of doing. Meanwhile, the accommodating and avoiding strategies were the most used by both nurses and physicians. Although these two strategies seem to be widely different from each other, they may be used in such situations where the two parties in conflict do not feel they are equivalent. In fact, the person using the avoiding strategy does not pursue personal concerns or the concerns of others by not addressing the conflict; while using the accommodating style neglects personal concerns to satisfy the concerns of others as mentioned very early by Kilmann and Thomas. ${ }^{[23]}$

A finding similar to this current study finding was shown by Ogunyemi, et al. ${ }^{[24]}$ in a study of conflict resolution strategies used by physicians in academic medicine, residents, and graduate medical education administrators in the United States, where avoiding was the most commonly used strategy, followed by compromising and accommodating. However, in disagreement with the present study finding, Losa Iglesias, et al. ${ }^{[25]}$ found that the compromising strategy was the most commonly used among nurses in Spain. The discrepancies might be attributed to differences in cultures and work climate between the current study and this Spanish one.

The relation between conflict resolution strategies and agree- 
ment upon conflict causes showed significantly less use of the competing strategy among the nurses and physicians who agreed upon conflict causes. This means that those who have a high perception of the possible causes of conflict are less prone to use this strategy. This might be due to that viewing the multiple causes of conflict, which might not have any foreseen solutions may deter from using this rather difficult win-lose resolution strategy. In agreement with this, Sportsman and Hamilton ${ }^{[26]}$ similarly reported low use of this strategy among health care professionals,

Moreover, among the physicians in the present study who agreed upon the conflict causes higher percentages were using the compromising, avoiding, and collaborating strategies. This might be related to the characteristics of these strategies which are less demanding in their application compared to the competing strategy. In congruence with this, Whitworth ${ }^{[27]}$ clarified that successful collaboration involves being able to manage one's emotions appropriately (selfmanagement) while using the awareness of the emotions of other people (social awareness) involved in the conflict to manage the conflict to a successful outcome (relationship management). This requires a high level of emotional intelligence, which may be lacking in the present study sample.

Meanwhile, none of the physicians in the emergency department was using the competing strategy, while the collaborating strategy was higher among the physicians was in the emergency department. This is expected given the nature of the work in emergency settings where team work is crucial for success. In line with this, Hoot and Aronsky ${ }^{[28]}$ in a systematic review demonstrated that emergency departments represent an international crisis due to the hectic workplace environment that needs real collaboration among various members of the health care team.

Regarding the factors influencing nurses and physicians' agreement upon the causes of conflict between them, the present study multivariate analysis identified that being a nurse was a positive independent statistically significant predictor of a higher score of agreement upon conflict causes, as compared with being a physician, and this increases the score by almost 4 points (beta coefficient $=3.66$ ). Other factors that independently and positively influence the score of agreement upon conflict causes, as identified in the present study are older age, female gender, and the more use of compromising strategy. Conversely, a longer experience is associated with a lower agreement score. However, in disagreement with this, Hendel, et al. ${ }^{[29]}$ showed no significant influence of physicians or nurses' characteristics on perception and resolution of conflicts. Hence, this may need further research.

\section{Conclusion}

In conclusion, nurses are more consenting upon most of the factors underlying the conflict between the two professions. Only the factors pertaining to workload are higher among physicians. The conflict resolution strategy most commonly used by both categories is the accommodating strategy, while more physicians use the compromising strategy. The nursing profession is a positive predictor of more agreement upon conflict causes, in addition to other factors as age, gender and experience years.

\section{Recommendation and future studies}

The study recommends the following: (1) Health professionals must develop communication and interpersonal skills and understanding of causes, approaches and strategies of conflict management. (2) Effective managing conflicts in a unit/ward requires using strategies such as confrontation, honest and open communication, ensuring clarity of responsibility. (3) Administrative should provide opportunities for discourse to help staff in solving conflicts between physicians and nurses, encourage more use of the collaboration strategy, and try to identify and eliminate the most common factors underlying the conflict between nurses and physicians. The present study provided a view for further studies such as: (1) Further clarification of causes of barriers to effective communication is essential in order to plan appropriate interventions. (2) More research is needed to investigate whether this cause of conflicts finding are associated with workload or not. (3) Future research is needed to develop preventive measures for the conflicts of health care professionals.

\section{REFERENCES}

[1] Sportsman S. Build a framework for conflict assessment. Nursing Management. 2005; 4(36): 32-40. http://dx.doi .org/10.1097 /00006247-200504000-00011

[2] Demir B, Kasapoğlu A. Nurse Physician Relations: A Qualitative Case Study in the Emergency Department of a Hospital in Ankara. European Journal of Turkish Studies. 2008; 3(30): 50-55.
[3] Afzalur MR. Managing Conflict in Organizations. Turkey: Transaction Publishers; 2010. 16 p.

[4] Fischer MD, Ferlie E. Resisting hybridisation between modes of clinical risk management: Contradiction, contest, and the production of in tractable conflict. Accounting Organizations and Society. 2013; 38(1): 30-49. http://dx.doi.org/10.1016/j.aos.2012.11.002

[5] Tabak N, Koprak O. Relationship between how Nurses resolve their 
Conflicts with Doctors, their Stress and Job Satisfaction. Journal of Nursing Management. 2007; 15(2): 321-331. PMID:17359432. http://dx.doi.org/10.1111/j.1365-2834.2007.00665.x

[6] Aghamolaei T, Tavafian SS, Hasani L, et al. Nurses' Perception of Nurse-physician Communication: A Questionnaire-based Study in Iran. International Journal of Hospital Research. 2012; 1(2): 77-84.

[7] Diab IA. The nature of nurse-physician relationships and its impact on their perception of nurse's role. Unpublished master thesis research, Faculty of Nursing, Cairo University. 2004; 69-72.

[8] Hotepo OM, Asokere SS, Abdul-Azeez IA, et al. Empirical Study of the Effect of Conflict on Organizational Performance in Nigeria. Business and Economics Journal BEJ. 2010; 12(2): 11-15.

[9] Shore LM, Chung-Herrera BG, Dean MA, et al. Diversity in organizations: Where are we now and where are we going? In Human Resource Management Review. 2009; 117-133.

[10] Cuddy AJC, Fiske ST, Glick P. The BIAS Map: Behaviors from intergroup affect and stereotypes. Journal of Personality and Social Psychology. 2009; 92(4): 631-648.

[11] Kilmanm RH, Thomas KW. Interpersonal conflict-handling behaviour as reflections of Jungian personality dimensions. Psychological Reports. 2003; 37(5): 971-980.

[12] Marquis BL, Huston CJ. Leadership roles and management functions in nursing: theory and application. 5th ed. Philadelphia, PA: Lippincott Williams \& Wilkins; 2006. 254-255 p.

[13] Thomas KW, Kilmann RH. Thomas-Kilmann Conflict Mode Instrument. Mountain View, CA: Xicom, a subsidiary of CPP, Inc. 2007.

[14] Jain A, Luo E, Yang J, et al. Implementing a nurse-shadowing program for first-year medical students to improve interprofessional collaborations on health care teams. Acad Med. 2012; 87(9): 1292-5

[15] McKie AE, Crowe A, McCombes W, et al. Dental nurses as trainers and assessors: vocational dental trainer attitudes. Eur J Dent Educ. 2010; 14(4): 235-46

[16] Svenaeus F. Empathy as a necessary condition of phronesis: a line of thought for medical ethics. Med Health Care Philos. 2014; 17(2): 293-9.

[17] McLennon SM, Uhrich M, Lasiter S, et al. Oncology nurses' narratives about ethical dilemmas and prognosis-related communication in advanced cancer patients. Cancer Nurs. 2013; 36(2): 114-121.
[18] Lyndon A, Zlatnik MG, Maxfield DG, et al. Contributions of clinical disconnections and unresolved conflict to failures in intrapartum safety. J Obstet Gynecol Neonatal Nurs. 2014; 43(1): 2-12.

[19] Cummings G, Olson K, Raymond-Seniuk C, et al. Factors influencing job satisfaction of oncology nurses over time. Can Oncol Nurs J. 2013; 23(3): 162-81.

[20] Muller-Juge V, Cullati S, Blondon K, et al. Interprofessional Collaboration between Residents and Nurses in General Internal Medicine: A Qualitative Study on Behaviours Enhancing Teamwork Quality. PLoS ONE. 2014; 9(4): e96160.

[21] McAndrew NS, Leske JS, Garcia A. Influence of moral distress on the professional practice environment during prognostic conflict in critical care. J Trauma Nurs. 2011; 18(4): 221-30.

[22] Di Giulio P, Cotta R, Bastianello D, et al. Doctors-nurses integration in paediatric onco-hematology: a cornerstone for quality of care. Report on a three years experienceGruppo PRIMIX. Assist Inferm Ric. 2004; 23(3): 142-8. PMID:15553329.

[23] Kilmann R, Thomas KW. Developing a forced-choice measure of conflict-handling behavior: The "MODE" instrument. Educational and Psychological Measurement. 1977; 37: 309-325. http: //dx.doi.org/10.1177/001316447703700204

[24] Ogunyemi D, Tangchitnob E, Mahler Y, et al. Conflict styles in a cohort of graduate medical education administrators, residents, and board-certified physicians. J Grad Med Educ. 2011; 3(2): 176-81.

[25] Losa Iglesias ME, Becerro de Bengoa Vallejo R. Conflict resolution styles in the nursing profession. Contemp Nurse. 2012; 43(1): 73-80.

[26] Sportsman S, Hamilton P. Conflict management styles in the health professions. J Prof Nurs. 2007; 23(3): 157-66. PMID:17540319. http://dx.doi.org/10.1016/j.profnurs . 2007.01.010

[27] Whitworth BS. Is there a relationship between personality type and preferred conflict-handling styles? an exploratory study of registered nurses in southern Mississippi. J Nurs Manag. 2009; 16(8): 921-932.

[28] Hoot NR, Aronsky D. Systematic Review of Emergency Department Crowding: Causes, Effects, and Solutions. Annals of Emergency Medicine. 2008; 52(2): 126-136.e1.

[29] Hendel T. Fish, Miri MA, Berger Ornit BA. Nurse/Physician Conflict Management Mode Choices: Implications for Improved Collaborative Practice. Nursing Administration Quarterly. 2007; 31(3): 244253. PMID:17607137. http://dx.doi.org/10.1097/01.NAQ. 0000278938.57115 .75 